\title{
sciendo
}

\section{Neurocognitive Functioning of Sport Climbers}

\author{
by \\ Milena Marczak1, Michat Ginszt², Piotr Gawda², Marcin Berger³, Piotr Majcher ${ }^{2}$
}

\begin{abstract}
Sport climbing, included in the programme of the Tokyo 2020 Summer Olympic Games, is increasingly gaining in popularity as a method of physical and mental health enhancement. Studies show a positive relationship between climbing and improvement of neurocognitive functioning. The aim of this study was to determine the differences in neurocognitive indicators: time of testing, memory, and location between climbers and non-climbers. The sample comprised 30 sport climbers (15 males, 15 females; aged $25 \pm 4$ years) practicing climbing regularly for five years, and 30 non-climbing age- and sex-matched controls. The Tactual Performance Test (Halstead-Reitan Test Battery) was used to measure neurocognitive functions (tactile-spatial functions, motion coordination, kinesthetic abilities, learning, memory). Significant differences were found between sport climbers and controls in reference to time, memory, and location $(p<0.05)$. Climbers reached higher memory as well as location ratios and lower time ratios in comparison to controls. Different strategies used to complete the task between the two groups were observed. The neurocognitive functioning of sport climbers manifests itself in faster recognition and differentiation of tactile input and better spatial perception, tactile perception, and movement memory.
\end{abstract}

Key words: neurocognitive functioning, sport climbing, Tactual Performance Test.

\section{Introduction}

Visual-spatial functions such as creating non-verbal information that allows for orientation in space improve adaptation to environmental conditions. In addition, visual-spatial functions are the basic aspect of knowing the world by perceiving the surrounding space, mental rotation, spatial visualization and the ability to predict the position of a moving object in space (Bednarek, 2004; Hegarty, 2011; Magiera, et al. 2013). In order to correctly perform visual-spatial activities, they must refer to proper basic cognitive functions such as perception, attention, memory, thinking, cognitive control and language. In the visual-spatial function, both cerebral hemispheres are involved (Sendrecka, 2007). During visual-spatial activation, the temporal, the parietal and the frontal lobe, as well as the temporal and parietal cortex are active
(Bueti and Walsh, 2009). In addition, the cerebellum plays an important role in the regulation of visual-spatial functions associated with spatial orientation, mental rotation of objects, and spatial memory (Starowicz-Filip et al., 2013). Visual and visual-spatial perception are related to the efficient functioning of visual receptors and eye movements. Identifying, copying, and searching for similarities are used when performing visual-spatial tasks (Possin, 2010). Active stimulation, environmental analysis, and the ability to detect errors are also important during visual-spatial activities (Gomez-Pinilla and Hillman, 2013). Moreover, one of the basic ways of acquiring information about the surrounding objects is touch perception, which is an important aspect of everyday functioning since birth. It includes the perception of pain, temperature,

\footnotetext{
1 - General Psychology, Department, Institute of Psychology, Maria Curie-Skłodowska University of Lublin, Poland.

2 - Department of Rehabilitation and Physiotherapy, Chair of Rehabilitation, Physiotherapy and Balneotherapy, Faculty of Health Sciences, Medical University of Lublin, Poland.

3 - Department of Functional Masticatory Disorders, Medical University of Lublin, Poland.
} 
proprioception, and perception of kinesthetic character (Fernandes and Albuquerque, 2012). Touch perception is also associated with the differentiation of texture and geometric shapes (Bergmann Tiest, 2010). In addition, vision and touch functions are automatically integrated for the perception of sequences of events (Bresciani et al., 2006).

Cognitive functions are weakened with progressive aging processes that are caused by neurodegenerative changes and cerebrovascular disease (Gottesman and Hillis, 2010; Querfurth and LaFerla, 2010). Disorders of visual-spatial orientation are present in Alzheimer's disease and may be its first symptoms (Possin, 2010; Weintraub et al., 2012). In mild cognitive impairments, visual-spatial abilities such as visual-motor coordination, psychomotor speed, visual synthesis, and structural praxis are decreased (Cho et al., 2015; Stegmayer et al., 2016; Wojtyńska, 2012). Changes in cognitive functioning also occur in terms of cognitive flexibility and planning, which are extremely important during visual-spatial tasks (Gardner et al., 2013).

For neuropsychological assessment of visual-spatial function, the Tactual Performance Test, the Benton Visual Retention Test (BVRT), the Rey-Osterrieth Complex Figure Test (ROCF), and the Ruff Figural Fluency Test (RFFT) are used (Kang et al., 2014; McIntyre et al., 2013; Steck, 2005). Clinical studies of tactile-spatial perception have so far focused on blind individuals (Postma et al., 2007), newborns and children with no linguistic features (Gallace and Spence, 2009), alcohol addicts (Charter, 2000) and healthy people considering sex as the differentiating variable (Heller et al., 2010). However, in the current literature, there is a lack of study of tactile-spatial perception in athletes.

Sport climbing, included in the programme of the Tokyo 2020 Summer Olympic Games, is increasingly gaining in popularity as a method of physical and mental health enhancement. Sport climbing improves overall physical fitness, muscle strength, visual-motor coordination, balance, muscle strength, endurance, sensory perception and mobility (Ginszt et al., 2017; Schnitzler, 2009; VoelckerRehage et al., 2011).

In addition, sport climbing improves the ability to search for new solutions, orientation and manipulation (Orth et al., 2016). Unlike other sports (running, cycling), sport climbing engages the cognitive and emotional resources of the individual (Luttenberger et al., 2015). Planning and executing motion sequences is a very important training element during sport climbing (Schram Christensen et al., 2017). Moreover, individual body movements are constantly monitored and modified to affect the overall motion, that requires visual, spatial, and psychomotor capabilities (Seifert et al., 2017). Hence, it can be assumed that sports climbing may improve neurocognitive functioning. However, in the current literature, there are no publications confirming the above assumptions.

Therefore, the purpose of this study was to determine the differences in neurocognitive indicators: time of testing, memory, and location between climbers and non-climbers.

\section{Methods}

The sample comprised 30 sport climbers (15 males, 15 females; aged $25 \pm 4$ years) practising climbing regularly ( 3 to 5 training days per week) for five years. All sport climbers included in the study group reached the rock climbing difficulty level $7 \mathrm{~b}$, based on the self-reported most difficult boulder problem/route ever climbed graded in the Font scale for bouldering and the French/sport scale for lead climbing. The age- and sex-matched control group (15 males, 15 females; aged $24 \pm 6$ years) consisted of individuals who did not practice sport in a targeted and systematic manner (they did not attend sports clubs, gyms, did not work with a coach). All participants ( $\mathrm{N}=$ 60) were right-handed (they declared themselves as right-handers and it corresponded to the hand they used to write).

All athletes and controls gave their informed consent to participate in the study. The study protocol was in accordance with the Declaration of Helsinki for Human Research.

The Tactual Performance Test (HalsteadReitan Test Battery) was used to measure neurocognitive functions (time, memory, location). The testing tool used was a wooden board of dimensions $45.5 \times 30.2 \times 2.1 \mathrm{~cm}$ with 10 cut-out geometric holes for 10 matched objects: a cross, a triangle, a semicircle, a circle, a rectangle, a hexagon, a diamond, a star, an oval, and a 
square (Figure 1). Each figure corresponded to one hole.

None of the participants saw the testing tool before or during the study. Prior to the measurement, all figures were randomized and distributed on a table. The first part of the study consisted of 3 trials. Just before the start of each task participants were informed what their specific task in that trial would be. In the first trial, the figures were to be placed in the appropriate test holes using the dominant hand (the right hand in our study). In the second attempt, the task was performed with the subordinate hand (in our study with the left hand). In the third attempt, the task was performed using both hands. After each test, the blocks were re-randomized.

The second part of the study was performed immediately after the first one under visual control. Participants were asked to draw on the paper all shapes of the figures that were memorized by touch in previous attempts. They were asked to draw the objects in their original layout. There were no time limits for this part of the test. In addition, there were no hints on the number, shape, and layout of the figures.
For the first part of the study, time of completion the task (in seconds) was the measure of performance. For the second part, the memory ratio corresponded to the number of correctly reconstructed figures on the paper by the participant (maximum of 10). The location ratio referred to the correct figure drawn on the card as close as possible to the board (maximum of 10).

IBM SPSS Statistics 21 software was used to perform statistical analysis. To compare the variables between the two groups, the MannWhitney $\mathrm{U}$ test and the Student's $\mathrm{t}$ test were used. The $p$-values $<0.05$ and $<0.01$ were considered statistically significant.

\section{Results}

Significant differences were found between sport climbers and controls in reference to memory, location, and both hands time ratios $(p<0.01)$ (Tables 1 and 2). A significant difference between the two groups was also found in the left-hand time ratio, right-hand time ratio, and total time ratio $(p<0.05)$ (Table 1). Sport climbers achieved higher memory and location ratios and lower time ratios.

\begin{tabular}{|c|c|c|c|c|c|c|}
\hline \multicolumn{7}{|c|}{$\begin{array}{c}\text { Table } \mathbf{1} \\
\text { Differences between sport climbers and the control group in the completion time } \\
\text { of the Tactual Performance Test (s) (Student's t test, Mann-Whitney U test) }\end{array}$} \\
\hline & \multicolumn{2}{|c|}{ Sport climbers } & \multicolumn{2}{|c|}{ Control group } & \multirow{2}{*}{$t / Z$} & \multirow{2}{*}{$p$} \\
\hline & $\mathrm{M}$ & SD & $\mathrm{M}$ & SD & & \\
\hline Right hand & 230.10 & 69.85 & 282.76 & 98.75 & $-1.996^{*}$ & 0.046 \\
\hline Left hand & 184.70 & 53.55 & 218.83 & 73.59 & $-2.054^{*}$ & 0.045 \\
\hline Both hands & 120.13 & 30.21 & 151.83 & 57.16 & $-2.685^{* *}$ & 0.010 \\
\hline Total time & 534.93 & 139.78 & 653.43 & 207.31 & $-2.596^{*}$ & 0.012 \\
\hline \multicolumn{7}{|c|}{${ }^{*} p<0.05 ;{ }^{* *} p<0.01$} \\
\hline
\end{tabular}



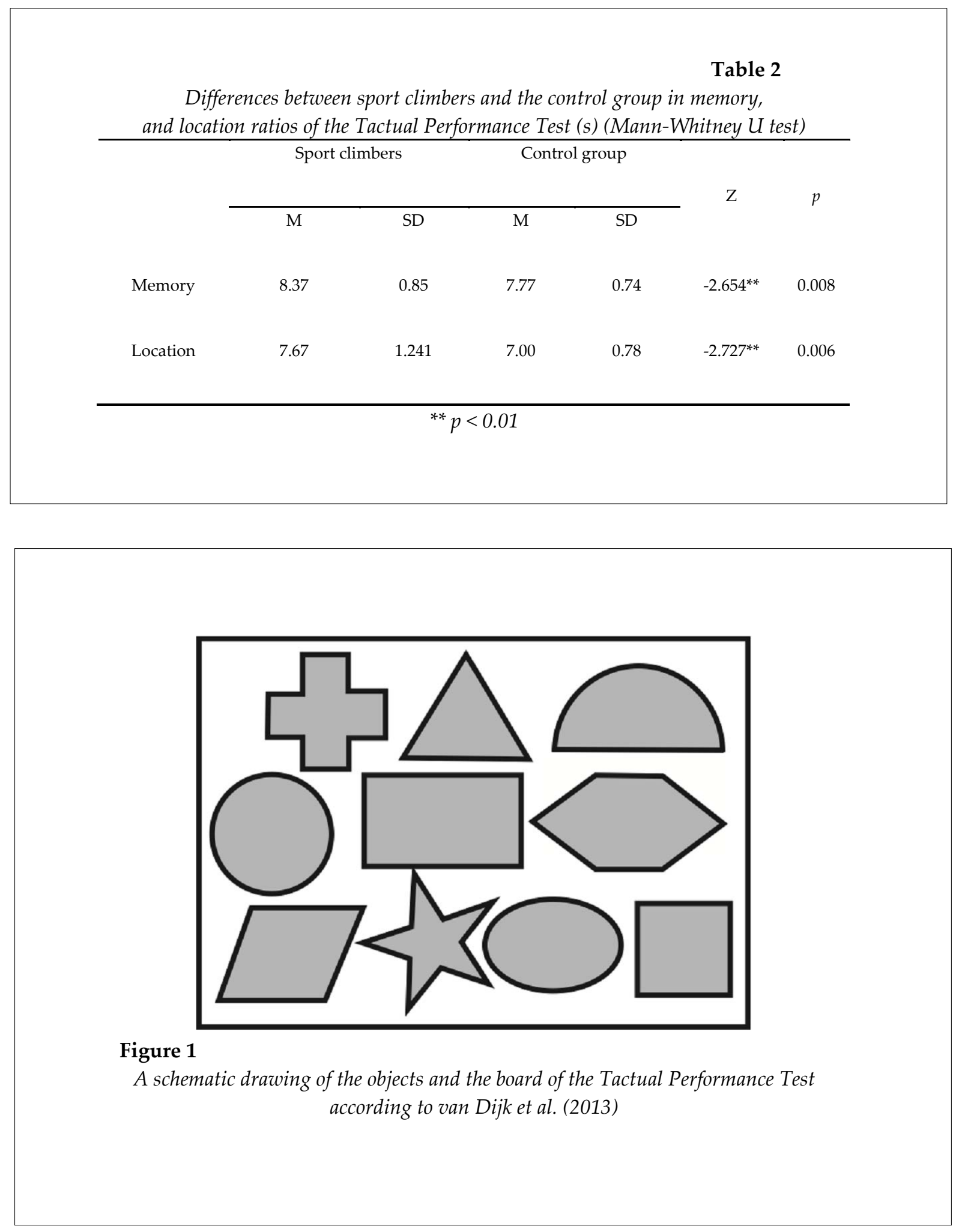

\section{Discussion}

Most people in the day-to-day routine prefer visual perception of the subject rather than touch perception (Newell et al., 2001). However, based on our results, sport climbers present a tendency to receive stimuli with activated both visual and tactile perception. This can be explained by the fact that sport climbers have more experience in the field of tactile and spatial perception of objects than non-climbers. Moreover, the Tactual 
Performance Test may be affected by coordination and memory skills, which is the indicator of the training effect between the individual tests (Steuden, 1994). To the best of our knowledge, this is the first report on neurocognitive indicators: time of testing, memory, and location not only in sport climbing, but also throughout themed sport activity.

In the present study, sport climbers achieved lower time ratios in comparison to nonclimbers. The results obtained in the Tactual Performance Test may be due to the ability of touch sensing and the ability to discriminate dispersive stimuli, which in sport climbers was at a higher level. The speed of performance by sport climbers can also be increased by the development of skills related to the search for new solutions (Orth et al., 2016). Among the studied groups, the use of different strategies during the Tactual Performance Test was observed, which may be the result of the level of neurocognitive functioning. Moreover, sport climbers achieved higher memory and location ratios in comparison to non-climbers. These results may prove better tactile-spatial perception in sport climbers. In addition, memory and location reconstruction of figures on a sheet of paper was dependent on the ability to recognize figures by touch, which indicates better tactile perception in sport climbers. Although a large and rapidly increasing number of studies have investigated physiological aspects of sport

\section{Acknowledgements} journal.

The results of the present study do not constitute endorsement of the product by the authors or the

\section{References}

Bednarek H. Differences of visual-spatial functions in a group of drivers with regard to the gender. Acta Univ. Lodz. Folia Psychol, 2004; 8: 147-156

Bergmann Tiest WM. Tactual perception of material properties. Vision Res, 2010; 50: 2775-2782

Bresciani JP, Dammeier F, Ernst MO. Vision and touch are automatically integrated for the perception of sequences of events. J. Vis, 2006; 6(5): 554-564

Bueti D, Walsh V. The parietal cortex and the representation of time, space, number and other magnitudes. Philos. Trans. R. Soc. B Biol. Sci, 2009; 364: 1831-1840

Charter RA. Item difficulty analysis of the tactual performance test trials. Percept. Mot. Skills, 2000; 91: 903909

Cho M, Kim D, Yang Y. Effects of visual perceptual intervention on visual-motor integration and activities of daily living performance of children with cerebral palsy. J. Phys. Ther. Sc, 2015; 27: 411-413

Dijk R, van Kappers AML, Postma A. Haptic Spatial Configuration Learning in Deaf and Hearing climbing, there is a lack of studies on neurocognitive functioning of sport climbers.

Sport climbing is used as a form of support for orthopedic, neurological, and psychological rehabilitation (Luttenberger et al., 2015). Climbing is also recommended for improving muscle stability and visual-motor coordination (Voelcker-Rehage et al., 2011). According to our results, it can also be assumed that sport climbing may assist in developing cognitive reserves in young people. Further research is recommended to determine whether climbing can be used as a method to support neuropsychological rehabilitation in patients with necessary to determine which features of climbing training have an influence on visual and spatial functioning in both healthy and cognitively impaired individuals.

\section{Conclusions}

The neurocognitive functioning of sport climbers manifests itself in faster recognition and differentiation of tactile input and better spatial perception, tactile perception, and movement memory. Further research is recommended to determine whether climbing can be used as a method to support neuropsychological rehabilitation in patients with cognitive impairment. 
Individuals. PLOS ONE, 2013; 8: e61336

Fernandes AM, Albuquerque PB. Tactual perception: a review of experimental variables and procedures. Cogn. Process, 2012; 13: 285-301

Gallace A, Spence C. The cognitive and neural correlates of tactile memory. Psychol. Bull, 2009; 135: 380-406

Gardner E, Vik P, Dasher N. Strategy use on the Ruff Figural Fluency Test. Clin. Neuropsychol, 2013; 27: 470484

Ginszt M, Berger M, Gawda P, Marczak M, Ginszt A, Majcher P. Electric activity of lumbar muscles in sport climbers. J. Educ. Health Sport, 2017; 7: 107-114

Gomez-Pinilla F, Hillman C. The Influence of Exercise on Cognitive Abilities. Compr. Physiol, 2013; 3: 403-428

Gottesman RF, Hillis AE. Predictors and assessment of cognitive dysfunction resulting from ischaemic stroke. Lancet Neurol, 2010; 9: 895-905

Hegarty M. The Cognitive Science of Visual-Spatial Displays: Implications for Design. Top. Cogn. Sci, 2011; 3 : 446-474

Heller MA, Jones ML, Walk AM, Schnarr R, Hasara A, Litwiller B. Sex differences in the haptic change task. J. Gen. Psychol, 2010; 137: 49-62

Kang H, Zhao F, You L, Giorgetta C, Sarkhel S, Prakash R. Pseudo-dementia: A neuropsychological review. Ann. Indian Acad. Neurol, 2014; 17: 147-154

Luttenberger K, Stelzer EM, Först S, Schopper M, Kornhuber J, Book S. Indoor rock climbing (bouldering) as a new treatment for depression: study design of a waitlist-controlled randomized group pilot study and the first results. BMC Psychiatry, 2015; 15: 201

Magiera A, Roczniok R, Maszczyk A, Czuba M, Kantyka J, Kurek P. The structure of performance of a sport rock climber. J Hum Kinet, 2013; 36: 107-17

McIntyre RS, Cha D, Soczynska J, Woldeyohannes H, Gallaugher L, Kudlow P, Alsuwaidan M, Baskaran A. Cognitive deficits and functional outcomes in major depressive disorder: Determinants, substrates, and treatment interventions. Depress. Anxiety, 2013; 30(6): 515-527

Newell FN, Ernst MO, Tjan BS, Bülthoff HH. Viewpoint dependence in visual and haptic object recognition. Psychol. Sci, 2001; 12: 37-42

Orth D, Davids K, Seifert L. Coordination in Climbing: Effect of Skill, Practice and Constraints Manipulation. Sports Med. Auckl. NZ, 2016; 46: 255-268

Possin KL. Visual Spatial Cognition in Neurodegenerative Disease. Neurocase, 2010; 16: 466-487

Postma A, Zuidhoek S, Noordzij ML, Kappers AML. Differences between early-blind, late-blind, and blindfolded-sighted people in haptic spatial-configuration learning and resulting memory traces. Perception, 2007; 36: 1253-1265

Querfurth HW, LaFerla FM. Alzheimer's disease. N. Engl. J. Med, 2010; 362: 329-344

Schnitzler EE. Letting go in order to move on--clinical report: therapeutic climbing in psychosomatic rehabilitation. Rehabil, 2009; 48: 51-58

Schram Christensen M, Jensen T, Voigt CB, Nielsen JB, Lorentzen J. To be active through indoor-climbing: an exploratory feasibility study in a group of children with cerebral palsy and typically developing children. BMC Neurol, 2017; 17(1): 112

Seifert L, Cordier R, Orth D, Courtine Y, Croft JL. Role of route previewing strategies on climbing fluency and exploratory movements. PLoS ONE, 2017; 12(4): e0176306

Sendrecka M. Different points of view of right and left hemispheres. Przeglad Psychol, 2007; 50: 149-164

Starowicz-Filip A, Milczarek O, Kwiatkowski S, Bętkowska-Korpała B, Piątek P. The role of the cerebellum in control of cognitive functions - neuropsychological perspective. Neuropsychiatr. Neuropsychol, 2013; 8: 24-31

Steck PH. A revision of A. L. Benton's Visual Retention Test (BVRT) in two parallel forms. Arch. Clin. 
Neuropsychol. Off. J. Natl. Acad. Neuropsychol, 2005; 20: 409-416

Stegmayer K, Bohlhalter S, Vanbellingen T, Federspiel A, Moor J, Wiest R, Müri R, Strik W, Walther S. Structural brain correlates of defective gesture performance in schizophrenia. Cortex J. Devoted Study Nerv. Syst. Behav, 2016; 78: 125-137

Steuden M. Test battery of Ward Halstead and his followers in neuropsychological diagnosis. Wybrane Zagadnienia z Neuropsychol. TN KUL Lub, 1994: 61-89

Voelcker-Rehage C, Godde B, Staudinger UM. Cardiovascular and Coordination Training Differentially Improve Cognitive Performance and Neural Processing in Older Adults. Front. Hum. Neurosci, 2011; 5: 26

Weintraub S, Wicklund AH, aSalmon DP. The Neuropsychological Profile of Alzheimer Disease. Cold Spring Harb. Perspect. Med, 2012; 2(4): a006171

Wojtyńska R. Recommendations for the screening and in-depth neuropsycho-logical examination in mild cognitive impairment (MCI). Psychogeriatria Pol, 2012; 9: 161-172

\section{Corresponding author:}

\section{Michał Ginszt}

Department of Rehabilitation and Physiotherapy, Chair of Rehabilitation, Physiotherapy and Balneotherapy, Faculty of Health Sciences, Medical University of Lublin, Poland

ul. Magnoliowa 2

20-143 Lublin, Poland

$+48602533723$

michal.ginszt@umlub.pl 